\title{
Comparison of Countries That Implement Blockchain Technology for National Logistics
}

\author{
Marhaeni $^{1}$, Yahaya Abd Rahim ${ }^{2}$, Nanna Suryana Herman ${ }^{3}$ \\ \{marhaeni@istn.ac.id ${ }^{1}$, yahaya@utem.edu.my ${ }^{2}$,nsuryana@utem.edu.my ${ }^{3}$, \\ Information System, Faculty of Science and Information Technology Institut Sains dan Teknologi \\ Nasional (ISTN) Jakarta Indonesia ${ }^{1}$ \\ Faculty Of Information and Communication Technology, Universiti Teknikal Malaysia Melaka (UTeM) \\ Melaka Malaysia $\mathbf{1 , 2 , 3}$
}

\begin{abstract}
Blockchain can be defined as distributed ledger technology that can securely and permanently record transactions between parties. The blockchain uses a shared database among many parties, the blockchain can eliminate the need for intermediaries who need to act as trusted third parties to validate, record and reconcile transactions. Some countries that have used Blockchain technology in various fields can be used as references to compare the implementation of blockchain technology in various fields with several indicators reviewed from several journal literature. In this study reviewed some countries that applied blockchain technology in several fields. Determination of several factors in comparing from the literature review. The results of this study are that the state obtained information in implementing technology which became a reference and motivation to be applied in Indonesia in accordance with the characteristics of the Indonesian state. Based on the comparison of this research, the advantages and disadvantages of the application of blockchain technology, especially in the field of logistics, are implemented in Indonesia
\end{abstract}

Keywords: Comparison, Blockchain Technology, National Logistics

\section{Introduction}

Bitcoin is the first concept of blockchain technology [1]. Blockchain technology is not only for Bitcoin, but also technology that can be applied in various fields. Blockchain technology is widely used in various fields. Blockchain has countless business ideas, applications, and startups in various areas such as healthcare, production, logistics, and agriculture [2]. Blockchain is a wide spread book/ledger with many potential programs [3]. Blockchain can be defined as distributed ledger technology that can securely and permanently record transactions between parties. With a shared database between many parties, blockchain essentially eliminates the need for an intermediary who needed to act as a trusted third party to validate, record and reconcile transactions. This study compares some countries with their characteristics in applying blockchain technology. Consists of paper according [4] Discussion on blockchain e-commerce-based agricultural development pathways in China. Even in the United States it is 
considered to have missed developing blockchain technology [2]. However, many developing countries have implemented blockchain faster than time in advanced economies. This is done because there are several reasons so that this technology is more quickly implemented. According to [2] there are two reasons as follows: First, the blockchain can help solve enormous challenges in developing countries but small problems in developed countries, such as unclear property rights or low use of bank accounts, blockchain has also been applied in transnational issues such as tracking refugees. Secondly, regulations in developing countries can become less complex and develop than in developed countries, enabling faster technology dissemination.

\section{Methodology}

The stages in this study can be seen in the following Figureure.1 :

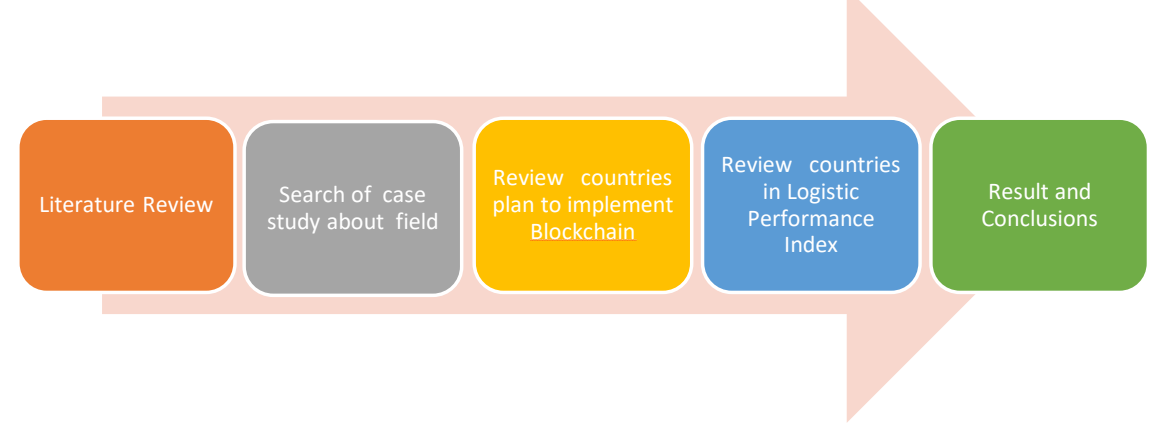

Figure. 1 Research Stage

The literature review stage collects the review literature obtained from related journals. The Search of a case study about field look for case studies according to the logistics that are applied in various countries. Review countries plan to implement Blockchain. And then conduct review countries in Logistic Performance Index so get results and conclusions.

\section{Literature Review}

\section{A Blockchain Technology}

Blockchain technology can be defined according to some literature as follows, according to [5] is Blockchain can be defined as distributed ledger technology that can securely and permanently record transactions between parties. With a shared database between many parties, blockchain essentially eliminates the need for an intermediary who needed to act as a trusted third party to validate, record and reconcile transactions. There is also a defining is Blockchain include data records or blocks. As each transaction occurs, it is put in a block. Each block is connected to it before and after it. Each block is added to the next irreversibly chain and transactions are locked together - thus the term "blockchain" [6]. The next definition also says 
The Blockchain is a disruptive innovation, due to its possibility of guaranteeing the immutability of data and public accessibility of data flows. Furthermore, its decentralized and distributed infrastructure prevents the problems of current centralized approaches, including trust issues, such as fraud, corruption, tampering and falsification of information and their limited resilience [7]. Blockchain Technology deals with similar transparency and traceability challenges. Its peer-to-peer structure facilitates any kind of transaction (eg, physical assets, money, intellectual property) without mediation according to sanders etc [9]. The three definitions state the existence distribute ledger technology, securely, permanently record, irreversibly, immutability, decentralized and distributed infrastructure [9]. These aspects can be seen in the picture as follows Figureure.2 :
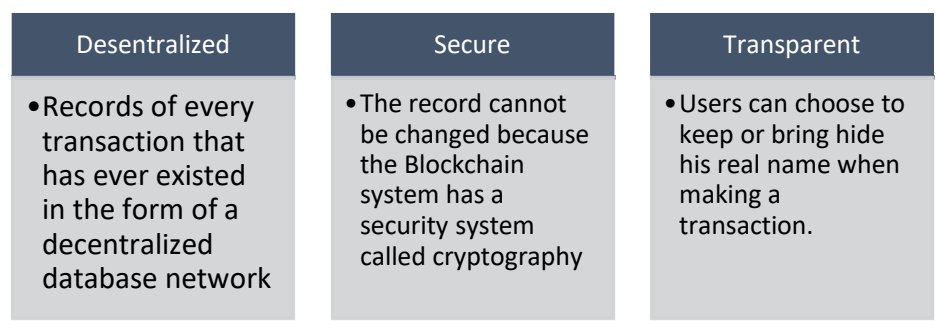

Figure.2 Basic Properties Of Blockchain

\section{Decentralized}

Records of every transaction that has ever existed in the form of a decentralized database network. Each existing transaction data is recorded in a block entity and each block is connected with a pre-existing block such as a chain.

\section{Secure}

If the transaction has been recorded in the database, the record cannot be changed because the Blockchain system has a security system called cryptography. This system is equipped with various algorithms that make all transactions arranged in chronological order and accessible to all. If you want to change the data of one transaction, then all data must be deleted and start all from the beginning.

\section{Transparent}

Each node or user in the Blockchain has an address that contains 30 alphanumeric characters or more for user identification marks (sort of username id). Users can choose to keep or bring hide his real name when making a transaction.

\section{B Countries with Plan Implement Blockchain}

Some countries have implemented blockchain technology in various sectors including China will develop blockchain technology for e-commerce in agriculture [4]. Furthermore, the United States implements business and star up in various sectors [2]. Likewise the Republic of Moldova wants to lift its country free from poverty and corruption with tourism 2.0 due to blockchain technology [10] and expected transparency system. In Uganda, developing countries have the potential to advance but do not have access to technology at this time, this is due to a lack of infrastructure so that this gap can be filled with blockchain technology [11]. In Indonesia, it has also begun to look at blockchain technology to be adopted in several sectors, one of which is in the marine sector, which is to form e-toll laut policy as a port management mechanism with blockchcain technology in Indonesia according to [12]. 
The above description can be seen from the table-1 below:

Table-1 Some Countries Planning Field to Implement Blockchain Technology

\begin{tabular}{lll}
\hline No & Country & Planning Field with Blockchain Technology \\
\hline $\mathbf{1 .}$ & China & E-commerce Agriculture \\
$\mathbf{2 .}$ & USA & Business and Star Up \\
$\mathbf{3 .}$ & Republic Moldova & Tourism 2.0 \\
$\mathbf{4 .}$ & Uganda & Infrastructure all sector \\
$\mathbf{5 .}$ & Indonesia & E-toll Laut \\
\hline
\end{tabular}

It can be seen that Indonesia has also planned blockchain technology in the marine sector in this according to [12] that Sea E-Toll in Indonesia as an e-governance solution to improve port management in Indonesia.

In addition to the countries above, you can also see ten countries which have embraced Blockchain Technology based on sources from [13]. The ten countries can be seen from the table-2 below:

Table-2 Countries Have Embraced Blockchain Technology

\begin{tabular}{|c|c|c|}
\hline No & Country & Have Embraced Blockchain Technology \\
\hline 1. & Australia & $\begin{array}{l}\text { The Australian Securities Exchange (ASX) announced that blockchain } \\
\text { technology will be fully adopted after two years after a two-year testing } \\
\text { period by removing all taxes from all transactions and trades, which are } \\
\text { carried out using cryptocurrency. }\end{array}$ \\
\hline 2. & China & $\begin{array}{l}\text { The Chinese government is open to adopting blockchain and Artificial } \\
\text { Intelligence (AI). It actively supports cryptocurrency platforms and } \\
\text { smart contracts such as Qtum, TRON, NEO, VeChain, and many others. }\end{array}$ \\
\hline 3. & Japan & $\begin{array}{l}\text { Japan is a bitcoin native country. Some retail stores in Japan accept } \\
\text { Bitcoin. }\end{array}$ \\
\hline 4. & $\begin{array}{l}\text { Dubai(United Arab } \\
\text { Emirate) }\end{array}$ & $\begin{array}{l}\text { Dubai is known as one of the richest and most technological countries } \\
\text { in the world. They have been researching blockchain technology and } \\
\text { transaction efficiency for many years now. }\end{array}$ \\
\hline 5. & Switzerland & $\begin{array}{l}\text { Zug, Switzerland, is home to some of the best blockchain companies in } \\
\text { the world. Zug is known as CryptoValley because it provides a powerful } \\
\text { platform for global cryptocurrency space growth in terms of } \\
\text { infrastructure, world-class talent and access to its encrypted local } \\
\text { government. }\end{array}$ \\
\hline 6. & Malta & $\begin{array}{l}\text { This Europen country is placed as a global leader because of its } \\
\text { progressive access to cryptographic curves. Cryptocurrencies accept as } \\
\text { a replacement. }\end{array}$ \\
\hline
\end{tabular}


7. USA

8. Estonia

9. United Kingdom

10. Singapore
In the first quarter of 2014, the US Revenue Service issued a guide to taxing Bitcoin operations and other virtual currencies. Bitcoin is treated as property when it comes to federal taxes.

The government has digitized its services using blockchain technology. The potential for Blockchain is increasing rapidly, and therefore many startups are starting their innovative blockchain projects.

The UK Government has been embracing blockchain technology in many ways. It houses the second-highest number of blockchain startups. The government is looking to implement blockchain in voting and healthcare systems.

The Singapore monetary authority (MAS) encourages adopting Blockchain technology in the financial sector for cross-border payments, insurance using smart contracts, building a secure health data system.

Based on the above description, the data concludes that some of the countries above have started implementing blockchain technology, where almost all countries use bitcoin and cryptocurrence from their country's financial sector. In addition, blockchain technology is used in various sectors for the future. Blockchain technology is still being developed and highlighted for future technology.

\section{Blockchain For National Logistics}

The geographical condition of the vast Indonesian archipelago and only $22 \%$ of its territory in the form of land is a very big challenge in the field of logistics [9] An important factor for the development of logistics in a country is the existence of an international hub, both maritime and air, as a center for the control of national and international goods flows. Some obstacles faced by national logistics according to [14] there are : (1). the low level of supply of infrastructure both in quant ity and quality, (2). there are still informal fees and transaction costs that cause high-cost economies, (3) the high time of export-import services and the obstacles to operational services at the port, (4) the limited capacity and service network of national logistics service providers

Based on the constraints on the national logistics system, a technology application is implemented, namely blockchain technology to assist in obtaining solutions in the field of national logistics. As a reference [15] in the 2018 Word Bank Logistics Performance Index (LPI), Indonesia ranked 46th with an LPI Score 3.15.

The top 5 countries are: Germany first, then Sweden, third in Belgium, fourth in Austria and fifth in Japan [15]. The score can be seen in the below Figurerue : 


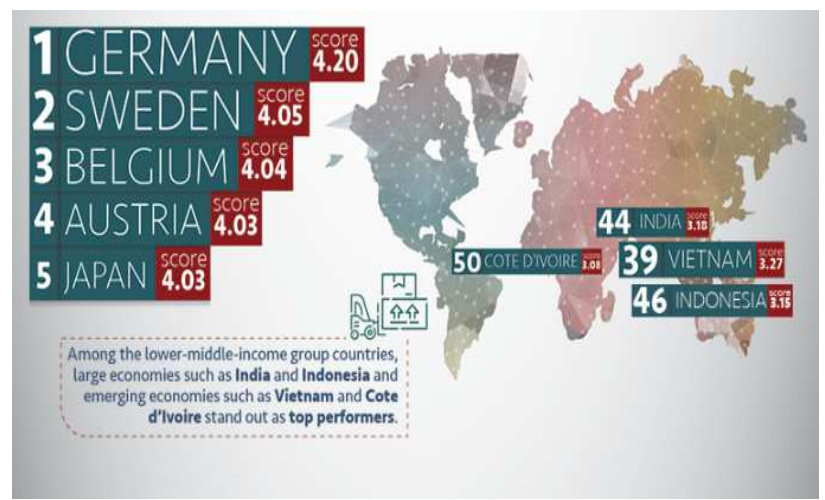

Figure. 2. The Top 5 Countries Ranking in Logistics Performance Index, 2018

In ASEAN Logistics Performance Index, Indones $0.63 \mathrm{cmia}$ is ranked 5th. The detailed data are as follows in table-2:

Table.2 Indonesia in ASEAN Logistics Performance The Word Bank Performance Index

\begin{tabular}{llllllll}
\hline Country & $\begin{array}{l}\text { LPI } \\
\text { Rank }\end{array}$ & $\begin{array}{l}\text { LPI } \\
\text { Score }\end{array}$ & $\begin{array}{l}\text { Cus- } \\
\text { toms }\end{array}$ & $\begin{array}{l}\text { Infra- } \\
\text { struc- } \\
\text { ture }\end{array}$ & $\begin{array}{l}\text { Inter- } \\
\text { national } \\
\text { Shipment }\end{array}$ & $\begin{array}{l}\text { Logistic } \\
\text { Com } \\
\text { petence }\end{array}$ & $\begin{array}{l}\text { Time } \\
\text { liness }\end{array}$ \\
\hline Singapore & 7 & 4.00 & 3.89 & 4.06 & 3.58 & 4.10 & 4.32 \\
Thailand & 32 & 3.41 & 3.14 & 3.14 & 3.46 & 3.41 & 3.81 \\
Vietnam & 39 & 3.27 & 2.95 & 3.01 & 3.16 & 3.40 & 3.67 \\
Malaysia & 41 & 3.22 & 2.90 & 3.15 & 3.35 & 3.30 & 3.46 \\
Indonesia & 46 & 3.15 & 2.67 & 2.89 & 3.23 & 3.10 & 3.67 \\
Philippines & 60 & 2.90 & 2.53 & 2.73 & 3.29 & 2.78 & 2.98 \\
\hline
\end{tabular}

Based on the table above, it can be seen that Indonesia is included in 5th place and in the aspect of Infrastructure, International Shipment and Logistics Competence Indonesia is still under the state of Singapore, Thailand, Vietnam, Malaysia. Thus Indonesia is still in dire need of attention in this aspect, but for the timeliness aspect of Indonesia the same as Vietnam, which is a score of 3.67, and that value is above Malaysia.

\section{Result and Discussion}

The results of this study are that the state obtained information in implementing technology which became a reference and motivation to be applied in Indonesia in accordance with the characteristics of the Indonesian state. Based on the comparison of this research, the advantages and disadvantages of the application of blockchain technology, especially in the field of logistics, are implemented in Indonesia. 


\section{Conclusions}

- Blockchain technology has begun to be highlighted in several countries, both developed and developing countries. In various fields plan to adopt blockchain technology, namely business, startup, agriculture, health, government, tourism, finance, logistics, and industry.

- In Indonesia, which is a developing country, it can be seen from the perspective of the advantages of blockchain technology, it can also adopt blockchain technology, especially in the logistics sector were in the mechanism that logistics in Indonesia still faces many obstacles.

- This can be seen from the rank of Indonesia in LPI so that it needs to be improved in order to compete with other developing countries. The aspects that still need to be considered are aspects of infrastructure, International Shipment, and Logistic Competence. This is because Indonesia belongs to the world maritime center.

- With blockchain technology which is a database decentralized, transparent, immutable, secure technology that is expected to improve the performance of Indonesia's logistics sector, this is part of the benefits of implementing blockchain technology, however, possible losses will be obtained when we implement this technology whether it is in accordance with the infrastructure of the country of Indonesia and government approval and policies as well as players involved in national logistics which are of particular concern to motivate whether blockchain technology can be implemented.

\section{Acknowledgements}

Thank you to all those who have assisted in writing this scientific journal article, greetings to Associate Professors Yahaya Abd Rahim and Professor. Nanna Suryana Herman from Faculty Of Information and Communication Technology, Universiti Teknikal Malaysia Melaka (UTeM) for enlightenment so that this paper is finished. 


\section{References}

[1] S. Nakamoto, "Bitcoin : A Peer-to-Peer Electronic Cash System," pp. 1-9.

[2] J. Robison, "Harnessing Blockchain for American Business and Prosperity Harnessing Blockchain for American Business and Prosperity," no. November, 2018.

[3] E. Tijan, S. Aksentijevi, and K. Ivani, "Blockchain Technology Implementation in Logistics," 2019.

[4] E. B. Blockchain, "Discussion on the Development Path of China's Agricultural Products," no. Eeec, pp. 91-95, 2018.

[5] M. Oude Weernink, W. Van Den Engh, M. Francisconi, and F. Thorborg, "The Blockchain Potential for Port Logistics," Erasmus Univ. Delft Univ. Technol., no. 2 January 2018, p. 16, 2017.

[6] Y. Wang, M. Singgih, J. Wang, and M. Rit, "Making sense of blockchain technology : How will it transform supply chains ?," no. November, pp. 0-12, 2018.

[7] G. Perboli, S. Musso, and M. Rosano, "Blockchain in Logistics and Supply Chain : A Lean Approach for Designing Real-World Use Cases," IEEE Access, vol. 6, pp. 62018-62028, 2018.

[8] F. Sander, J. Semeijn, D. Mahr, and D. Mahr, "The acceptance of blockchain technology in meat traceability and transparency," 2018.

[9] W. Kersten, T. Blecker, C. M. Ringle, N. Hackius, and M. Petersen, "Published in: Digitalization in Supply Chain Management and Logistics Blockchain in Logistics and Supply Chain: Trick or Treat? Blockchain in Logistics and Supply Chain: Trick or Treat?," 2017.

[10] M. Pilkington, C. U. D. B. Franche-comté, and L. G. Grant, "Blockchain and bitcoin as a way to lift a country out of poverty - tourism 2.0 and e-governance in the Republic of Moldova Rodica Crudu," vol. 7, no. 2, 2017.

[11] E. Ahishakiye, R. Wario, and I. Niyonzima, "Developing Countries and Blockchain Technology : Uganda 's Perspective Developing Countries andBlockchain Technology : Uganda's Perspective," no. August, 2018.

[12] J. R. B. Km et al., "E-Toll Laut : Blockchain Port as the Key for Realizing Indonesia 's Maritime Fulcrum,” pp. 36-45, 2019.

[13] "Blockchain Council." [Online]. Available: https://www.blockchaincouncil.org/blockchain/top-10-countries-leading-blockchain-technology-in-the-world/.

[14] P. N. 26, “PerPres No 26, 2012,” 2012.

[15] “The Word Bank Logistics Performance Index." [Online]. Available: https://lpi.worldbank.org/international/global/2018. 